\begin{tabular}{|l|l|l||}
\hline \multicolumn{2}{|c|}{ PublisherInfo } \\
\hline \hline PublisherName & $:$ & BioMed Central \\
\hline \hline PublisherLocation & $:$ & London \\
\hline \hline PublisherImprintName & $:$ & BioMed Central \\
\hline \hline
\end{tabular}

\title{
RNAi in mammals
}

\begin{tabular}{|l|l|l||}
\hline \multicolumn{2}{|c|}{ ArticleInfo } \\
\hline \hline ArticleID & $:$ & 3912 \\
\hline \hline ArticleDOI & $:$ & $10.1186 /$ gb-2001-2-3-reports0007 \\
\hline \hline ArticleCitationID & $:$ & reports0007 \\
\hline \hline ArticleSequenceNumber & $:$ & 17 \\
\hline \hline ArticleCategory & $:$ & Paper report \\
\hline ArticleFirstPage & $:$ & 1 \\
\hline \hline ArticleLastPage & $:$ & 4 \\
\hline \hline & & RegistrationDate : 2001-1-5 \\
ArticleHistory & $:$ & Received \\
& & OnlineDate 2001-1-5 \\
\hline \hline ArticleCopyright & $:$ & BioMed Central Ltd2001-2-28 \\
\hline \hline ArticleGrants & $:$ & \\
\hline \hline
\end{tabular}




\begin{tabular}{|l|l|l||}
\hline ArticleContext & $:$ & 130592233 \\
\hline
\end{tabular}

\section{Edupalli Subbaiah Venkata}

\section{Abstract}

A method for double-stranded RNA interference of gene expression in mammalian cells.

\section{Significance and context}

Introduction of the appropriate double-stranded RNA (dsRNA) to a model organism can interfere with the expression of the corresponding gene, a process known as RNA interference (RNAi). The dsRNA dominantly silences gene expression in a sequence-specific manner by causing the corresponding endogenous mRNA to be degraded. Both sense and antisense strands have distinct roles in the way in which dsRNA triggers RNAi. The technique was first developed in Caenorhabditis elegans, and was rapidly applied to a wide range of organisms, including Drosophila melanogaster, Hydra, planarians, Trypanosoma brucei, plants, fungi and zebrafish embryos (with limited success in the latter). RNAi in mouse embryos could be a way of eliminating specific gene expression in particular tissues or developmental stages, as an alternative to classical techniques of homologous recombination (gene 'knockout') which eliminate the function of a gene throughout the embryo. But can RNAi be truly effective in mammalian cells? Wianny and Zernica-Goetz have assessed the effectiveness of RNAi in mouse embryos by demonstrating that microinjection of the appropriate dsRNA can phenocopy of the effects of specific disrupted gene expression.

\section{Key results}

The authors first tested interference with the expression of a green fluorescent protein (GFP) transgene, $M m G F P$. Co-injection of capped full-length $M m G F P$ mRNA and $M m G F P$ dsRNA specifically inhibited $M m G F P$ expression, resulting in diminution or abolition of green fluorescence, relative to levels after infection of only the transgene. The authors next showed that injection of $E$ cadherin dsRNA leads to a striking reduction in amounts of E-cadherin protein and a similar phenotype to E-cadherin gene knockout. They also showed that injected dsRNA was able to block the expression of a maternally-expressed gene, $c$-mos. Injection of $c$-mos dsRNA into mouse oocytes specifically interferes with $c$-mos activity, mimicking the targeted deletion of $c$-mos by knockout. 


\title{
Links
}

More information on RNAi and its applications can be found at the RNA combinatorial biochemistry website, Jack Dixon's lab, the laboratory of Richard Schultz, and RNAi protocols and vector information from the laboratory of Andrew Z Fire can be downloaded from the Fire lab vector/RNAi information ftp site.

\section{Conclusions}

This work addresses concerns about the effectiveness of RNAi in mammals by showing that RNAi following injection of dsRNA in mouse embryos is specific to the corresponding gene and does not cause a general translational arrest (as can occur in some viral infections); the embryos continue to develop without any signs of cell death. The authors show that RNAi acts in the mouse either by inducing degradation of the targeted RNA or by inhibiting its translation.

\section{Reporter's comments}

RNAi provides new avenues for studying loss-of-function phenotypes in particular cells and at particular stages of development of the early mouse embryo. It should be possible to study loss of function of combinations of genes as well as of single genes. Effective RNAi in domestic animals and humans could be useful because it might overcome the ethical difficulties in creating permanent germline loss-of-function mutants. Heritable and inducible RNAi are widely considered the most promising approaches to determining gene function through systematic gene silencing. It should also help to develop a more comprehensive view of relationships between the genome, gene function, and the environment.

\section{Table of links}

\author{
Nature Cell Biology \\ RNA combinatorial biochemistry \\ Jack Dixon's lab \\ Richard Schultz
}


Fire lab vector/RNAi information

\section{References}

1. Wianny F, Zernica-Goetz M: Specific interference with gene function by double-stranded RNA in early mouse development. Nat Cell Biol. 2000, 2: 70-75. 1465-7392 